\title{
A configuração da docência expressa no projeto pedagógico do curso de Pedagogia: um estudo de caso
}

\section{The configuration of teaching in the teaching project of the Pedagogy course: a case study}

\author{
Maria Irene Miranda* \\ Mônica Luiz de Lima Ribeiro*
}

\begin{abstract}
Resumo: Este artigo tem por objetivo refletir sobre como a concepção de docência, preconizada nas Diretrizes Curriculares Nacionais para o Curso de Graduação em Pedagogia - DCNP (2006) e defendida especialmente pela Associação Nacional pela Formação dos Profissionais da Educação - Anfope, está configurada no Projeto Pedagógico do Curso de Pedagogia de uma Instituição de Educação Superior - IES pública. O estudo pautou-se na pesquisa qualitativa, no viés do estudo de caso instrumental (ANDRÉ, 2005), e teve como procedimento investigativo a análise de documentos e entrevistas semiestruturadas, além de revisão bibliográfica constante. A partir da análise das informações coletadas, evidenciamos que a configuração da docência no Projeto Pedagógico do curso pesquisado, tendo por base os princípios supracitados, provocou: reestruturação da grade curricular e das atividades acadêmicas; redimensionamento dos conteúdos trabalhados; introdução de novas modalidades pedagógicas; inserção do estudante no campo de atuação desde os anos iniciais; pensamento e ação interdisciplinar, unidade teoria e prática. Contudo, ressaltamos que grande parte do trabalho individual e coletivo do professor é responsável pelo êxito do desenvolvimento da docência como base comum - articulada à pesquisa e à gestão e configurada no PPC de Pedagogia analisado.
\end{abstract}

Palavras-chave: Diretrizes Curriculares Nacionais. Projeto pedagógico. Curso de pedagogia. Docência.

\begin{abstract}
This article reflects on how the concept of teaching proposed in the Brazilian National Curriculum Guidelines - DCNP 2006 - for the Pedagogy Course and supported especially by Anfope (National Association for the Education of the Professionals of Education) is set in the Teaching Project of the pedagogy course of a public Institution of Higher Education. The qualitative research, in the form of an instrumental case study (André, 2005) included document analysis and semi-structured interviews, as well as the constant review of the literature. The configuration of teaching as a national common ground implies the confluence of a set of principles that should guide the curriculum. It should include: the relation between theory/practice and the emphasis on research and knowledge production; solid theoretical formation and interdisciplinary; democratic management; social political and ethical commitment; collective and interdisciplinary work and the incorporation of the concept of continuing education. From the analysis of the data collected, it was concluded that the configuration of teaching in the Pedagogy Course researched is based on the above principles which led to: restructuring the curriculum and academic activities; resizing of contents; introduction of new teaching methods; engaging students in their future working context since the early years; interdisciplinary thought and action; unity theory-practice. However, it should be emphasized that much of the individual and collective work of
\end{abstract}

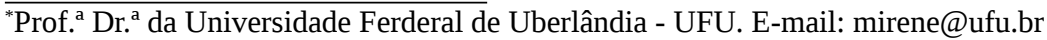

* Professor at the Federal University of Uberlândia - UFU. E-mail: mirene@ufu.br

** Prof. ${ }^{\text {a }}$ Mestre da Universidade Federal de Uberlândia - UFU. E-mail: monicaribeiro10@yahoo.com.br

** Professor at the Federal University of Uberlândia - UFU. E-mail: monicaribeiro10@yahoo.com.br
} 
teachers is responsible for the successful development of teaching as a common base - articulated to research and the management of the Pedagogy Course studied.

Keywords: National curriculum guidelines. Teaching project. Pedagogy course. teaching.

\section{Introdução}

O presente estudo começou a ser desenvolvido em um momento oportuno. Em maio de 2006, as DCNP foram aprovadas pelo Conselho Nacional de Educação - CNE, por meio da Resolução $n^{\circ}$. 1/2006. Ao serem aprovadas, tais Diretrizes reacenderam a discussão em torno das funções do profissional pedagogo e indicaram a necessidade de um novo Projeto Pedagógico $^{1}$ para os cursos de Pedagogia, que fosse assentado numa base comum, compreendida na perspectiva da docência.

Esse assunto se constitui numa discussão histórica, sendo debatido, pelo movimento de educadores, desde o final da década de 1970 e início da década de 1980, em específico na I Conferência Brasileira da Educação - CBE (1983). A docência, a cada encontro promovido, especialmente pela Anfope, sempre foi um princípio explicitado com mais ênfase. Era constantemente reafirmada nas reuniões, no sentido de ser definida com maior exatidão. No bojo das discussões realizadas pelas entidades do campo educacional e também pelas Comissões de Especialistas do Ensino de Pedagogia - CEEP - a docência não deveria ser expressa como um currículo mínimo, mas como uma concepção básica de formação do educador.

A compreensão da docência na forma como está anunciada nas Diretrizes não se limita,unicamente, ao ato de ministrar aula. No entanto, alguns teóricos do campo da

\footnotetext{
${ }^{1}$ Esse Projeto já está em fase de construção, implementação e/ou avaliação em muitas instituições.
}

educação não advogam essa concepção alargada de docência. Para Libâneo (2006, p. 220): "A ciência que tem por objeto o ensino, a docência, é a Didática”. Para esse autor, a base de um curso de Pedagogia deveria ser o estudo do fenômeno educativo em sua complexidade.

O estudo de Cruz (2008) revelou, também, uma preocupação de seus entrevistados com relação à ampliação do conceito de docência explicitado nas DCNP. De acordo com a autora:

\section{[...] a complexidade parece não residir na docência, mas no receio de secundariza- ção da própria pedagogia, uma vez que a docência, como base, passa a ser o eixo estruturante de todo o curso. Nesse sen- tido, um aspecto focalizado pelos entre- vistados, inclusive por aqueles que não veem problema na docência como base de formação do pedagogo, diz respeito ao conceito de docência subjacente no texto das diretrizes curriculares para o Curso de Pedagogia. (CRUZ, 2008, p. 153).}

Outros autores comungam da ampliação reservada à docência no texto das DCNP. Para Martins (2009, p. 8), “[...] temse, assim, a possibilidade de ampliar o ato educativo da docência para uma atividade educativa de fato, em seu sentido mais pleno e não circunscrito à escola”. Aguiar e outros (2006) também enfatizam que a concepção de docência, ao ser expandida, possibilita uma articulação com a ideia de trabalho pedagógico. 
Mesmo não havendo acordo em torno da docência como base comum, que envolve a gestão, a produção e difusão do conhecimento, para Triches (2007, p. 14) parece "[...] não restar dúvida de que a docência é a questão-chave que define a identidade e ação do profissional formado nesse novo curso de Pedagogia, ou seja, é hegemônica”.

A partir desse cenário, realmente se constitui um desafio pesquisar sobre o curso de Pedagogia e a (re)construção de Projetos Pedagógicos para ele com base na docência, pois além de ser uma perspectiva recente, ainda não há consenso em torno da sua concepção. Além disso, as DCNP, conforme Saviani (2008), com quem concordamos,

[...] são, ao mesmo tempo, extremamente restritas e demasiadamente extensivas: muito restritas no essencial e assaz excessivamente no acessório. São restritas no que se refere ao essencial, isto é, àquilo que configura a pedagogia como um campo téorico-prático [sic] dotado de um acúmulo de conhecimentos e experiências resultantes de séculos de história. Mas são extensivas no acessório, isto é, dilatam-se em múltiplas e reiterativas referências à linguagem hoje em evidência, impregnada de expressões como conhecimento ambiental-ecológico [sic]; pluralidade de visões de mundo; interdisciplinaridade, contextualização, democratização [...]. (SAVIANI, 2008, p. 67).

Tendo em vista todas essas variáveis dentro do contexto do curso de Pedagogia e considerando as transformações advindas de organismos internacionais que interferem na política educacional, concordamos com Malanchen e Vieira (2006, p.2) de que hoje se exige "[...] maior eficiência e produtividade dos trabalhadores a fim de que eles se adaptem mais facilmente às exigências do mercado”.
Autores como Catani, Oliveira e Dourado (2001), Rodrigues e Küenzer (2006), ajudam a compreender como as variáveis no curso de Pedagogia estão ligadas às mudanças na sociedade capitalista e às novas demandas do mercado de trabalho, que exigem, cada vez mais, maior flexibilidade profissional.

Assim, realmente (re)configurar, elaborar um Projeto Pedagógico para o curso de Pedagogia não é tarefa fácil. Quanto mais nos aprofundamos no contexto do curso de Pedagogia, é possível verificar que ele teve a sua gênese e evolução histórica marcadas pela imposição dos currículos mínimos; teve suas Diretrizes construídas por um longo e conturbado processo político e ideológico; e apresenta no seu texto, além de imprecisões teóricas, artigos que geram consenso e dissensos, em especial com relação à concepção de docência. De tal modo, questionamos: como o curso de Pedagogia poderá expressar, em seu Projeto Pedagógico, uma compreensão de docência enquanto base, sendo que esta apresenta um longo e inconcluso processo de construção?

Esse processo parece oportunizar debates inesgotáveis sobre o curso de Pedagogia, porém este artigo não tem a pretensão de esgotar as discussões, mas trazer contribuições para esse campo de formação, a partir da reflexão sobre como a concepção de docência, preconizada nas DCNP e defendida, sobretudo, pela Anfope, está configurada no Projeto Pedagógico do curso de Pedagogia de uma IES pública.

De tal forma, o estudo se pautou na pesquisa qualitativa, no viés do estudo de caso instrumental (ANDRÉ, 2005), e teve como procedimento investigativo a análise de documentos e entrevistas semiestruturadas, além da revisão bibliográfica constante. 


\section{Uma breve contextualização da docência}

Etimologicamente, a palavra docência vem do latim docére e significa ensinar, instruir, mostrar, indicar, dar a entender (HOUAISS, 2004). Porém, a partir das discussões promovidas, particularmente, pelas entidades da área educacional ${ }^{2}$, a concepção de docência foi ampliada para além da sala de aula, ou seja, não se limita ao simples ato de ministrar aula, transmitir um conteúdo por meio de técnicas deslocadas de um contexto macro.

Os artigos 1, 2 e 4 das DCNP mostram a relevância atribuída à docência na sua forma ampliada, que articula ensino, gestão e pesquisa. O primeiro explicita claramente a modalidade do curso de Pedagogia na direção do ensino. $\mathrm{O}$ art. 2 define que essa licenciatura está voltada para o exercício da docência na Educação Infantil, nos anos iniciais do Ensino Fundamental, nos cursos de Ensino Médio, na modalidade Normal, em cursos de Educação Profissional na área de serviços e apoio escolar e outras áreas que exijam conhecimentos pedagógicos. Ainda no art. 2, § 1, a docência é ampliada, deixa de ser simplesmente a prática, em sala de aula, do exercício na Educação Infantil, Anos Iniciais e outros níveis e modalidades de ensino, e passa a ser compreendida como:

[...] ação educativa e processo pedagógico metódico e intencional, construído em

\footnotetext{
${ }^{2}$ Ao mencionar entidades/associações do campo/área educacional, referimo-nos à Associação Nacional de Pesquisa e Pós-Graduação em Educação - Anped; à Associação Nacional de Políticas e Administração em Educação - Anpae; ao Fórum Nacional dos Diretores das Faculdades, aos Centros de Educação das Universidades Públicas Brasileiras - Forumdir; à Associação Nacional para a Formação Profissional de Educadores - Anfope e ao Centro de Estudos Educação $\&$ Sociedade - Cedes.
}

relações sociais, étnico-raciais e produtivas, as quais influenciam conceitos, princípios e objetivos da Pedagogia, desenvolvendo-se na articulação entre conhecimentos científicos e culturais, valores éticos e estéticos inerentes a processos de aprendizagem, de socialização e de construção do conhecimento, no âmbito do diálogo entre diferentes visões de mundo. (BRASIL, 2006, p. 1).

Essa compreensão de docência ainda abarca como parte da atividade docente outros campos de atuação como, por exemplo, a área da gestão e pesquisa, conforme se menciona no art. 4, § único:

As atividades docentes também compreendem participação na organização e gestão de sistemas e instituições de ensino, englobando:

I - planejamento, execução, coordenação, acompanhamento e avaliação de tarefas próprias do setor da Educação;

II - planejamento, execução, coordenação, acompanhamento e avaliação de projetos e experiências educativas não-escolares; III - produção e difusão do conhecimento científico-tecnológico do campo educacional, em contextos escolares e nãoescolares. (BRASIL, 2006, p. 2).

Mesmo não havendo nas DCNP um registro explícito de que a docência seja a base da formação do curso de Pedagogia, ao desenvolver um estudo sobre o seu processo de construção, pode-se concluir que é. A proposição da docência no texto das DCNP foi uma reivindicação da própria Anfope e entidades da área educacional, as quais construíram a proposta coletivamente com professores, pesquisadores interessados na formação do profissional da educação, durante décadas, resultante de lutas, embates e conflitos políticos e ideológicos. Ou seja, a influência da Anfope não foi um processo linear. 
Dessa forma, partimos do pressuposto de que a docência preconizada nas DCNP incorpora em si os princípios defendidos pela Anfope. Assim, analisamos a configuração da docência tendo como referenciais as discussões travadas no âmbito dessa entidade, pois segundo ela $(1994$, p. 11), “[...] à medida que se aprofundam os estudos sobre os princípios norteadores do movimento, foi explicitando-se o conceito de base comum nacional". Ou seja, a docência como base comum nacional implica a confluência de um conjunto de princípios que devem nortear a organização curricular, que inclui: relação teoria e prática e ênfase na pesquisa como produção de conhecimento; sólida formação teórica e interdisciplinar; gestão democrática; compromisso social, político e ético; trabalho coletivo e interdisciplinar; e incorporação da concepção de formação continuada. Tal processo será discutido a seguir.

\section{Entre fios e teias: a configuração da docência a partir dos princípios norteadores}

Durante o desenvolvimento do curso de Pedagogia, em geral, sempre se criticou a questão da fragmentação teoria e prática presente na organização curricular, ou seja, primeiro se ensina os fundamentos da educação tais como Filosofia, Sociologia, e depois os conhecimentos específicos como, por exemplo, Metodologias, Didática e Estágio. Essa organização linear do currículo, do geral para o particular, é consequência da concepção positivista do conhecimento predominante nos cursos de nível superior. A ideia que sustenta essa concepção afirma:

[...] que, primeiro, o aprendiz precisa dominar a teoria para depois entender a prática e a realidade. Ela tem definido a prática como comprovação da teoria e não como sua fonte desafiadora, localizando-se, quase sempre, no final dos cursos, em forma de Estágio. Além disso, trabalha-se com o conhecimento do passado, com a informação que a ciência já legitimou, nunca com os desafios do presente ou com o conhecimento empírico que pode nos levar ao futuro. (CUNHA 2000, p.28).

Essa visão da teoria desconexa da prática subentende que esta é uma aplicação daquela, deixando transparecer uma pseudovalorização do que é teórico sobre o que é prático. Na verdade, a teoria e a prática se amparam numa relação de reciprocidade, uma depende intrinsecamente da outra, conforme enfatiza Vázquez (1977, p. 202): “A atividade teórica em seu conjunto - como ideologia e ciência - considerada também ao longo de seu desenvolvimento histórico, só existe por e em relação com a prática, já que nela encontra seu fundamento, suas finalidades e seu critério de verdade”.

Nessa perspectiva, não existe teoria desvinculada da prática, a qual, além de ser fonte para a dimensão teórica evidenciando elementos presentes na realidade é, ainda, segundo Vázquez (1977), tida como finalidade da atividade teórica, “[...] como antecipação ideal de uma prática que ainda não existe” (p. 202).

Ao fazer a leitura dos Documentos Finais dos Encontros da Anfope, nota-se que essa questão da unidade teoria e prática, ao longo dos cursos que formam os profissionais da educação, sempre esteve presente na pauta das discussões. A Anfope tem defendido que essa relação deve perpassar todo o curso de formação do educador e não ser limitada a uma disciplina, em geral, Prática de Ensino e/ou Estágio, e nem a um momento particular do currículo.

Nessa direção, a unidade teoria e prática foi entendida e configurada no PPC de 
Pedagogia da IES em foco como permanente articulação entre formação teórica desenvolvida e realidade educacional vivenciada. Os conteúdos foram redirecionados na tentativa de romper com a separação entre teoria e prática. A proposição dessa mudança não acarreta apenas reestruturação de disciplinas, pois modifica a estrutura de um curso que, desde sua institucionalização, se organizava com fundamentos da educação no início e os conhecimentos específicos no final. No entanto, querer mudar uma tradição ou cultura gera inseguranças e ansiedade, pois, além de não ser uma transformação instantânea e linear, dependerá, significativamente, do uso e funções que os atores envolvidos exercerão sobre esse processo, ou seja, da prática desenvolvida pelo professor no desenrolar dos conhecimentos.

Nesse sentido, tencionando superar a fragmentação teoria e prática, os professores envolvidos com a edificação do PPC se utilizaram do Projeto Integrado da Prática Educativa - Pipe - proposto pelo Projeto Institucional de Formação e de Desenvolvimento do Profissional da Educação, da IES pesquisada, em atendimento às Resoluções CNE/CP n ${ }^{\circ}$. 01/2002 e 02/2002 ${ }^{3}$.

\footnotetext{
${ }^{3}$ A Resolução CNE/CP n ${ }^{\circ}$ 01/2001 e a Resolução CNE/ $\mathrm{CP} \mathrm{n}^{\circ}$ 02/2002 instituíram as Diretrizes Curriculares Nacionais para a Formação de Professores da Educação Básica, em nível superior, a duração e a carga horária dos cursos de licenciatura, de graduação plena, de formação de professores da Educação Básica em nível superior, respectivamente. A primeira dispôs no seu artigo 12 a questão da prática: " $\S 1^{\circ} \mathrm{A}$ prática, na matriz curricular, não poderá ficar reduzida a um espaço isolado, que a restrinja ao estágio, desarticulado do restante do curso. $\S 2^{\circ}$ A prática deverá estar presente desde o início do curso e permear toda a formação do professor. $\S 3^{\circ}$ No interior das áreas ou das disciplinas que constituírem os componentes curriculares de formação, e não apenas nas disciplinas pedagógicas, todas terão a sua dimensão prática”. E continuou no artigo 13: "Em tempo e espaço curricular específico, a coordenação da dimensão prática transcenderá o estágio e terá como finalidade promover
}

O Pipe foi apropriado pelo curso de Pedagogia para ser trabalhado na primeira e segunda série. Ele não é um componente predefinido. Se entendermos “Projeto" como um plano, uma construção a se realizar, e "Integrado" no sentido de unir, formando um todo harmonioso, não há como listar a priori o que deve ser trabalhado no Projeto de Prática Educativa como se propõe para as disciplinas. Assim temos como pressuposto que esse componente curricular deveria ser construído coletivamente na dinâmica do curso, no movimento das disciplinas, das práticas educativas e do diálogo entre os professores.

A inserção do Pipe no curso de Pedagogia é uma exigência legal - como sinalizamos acima - e foi redirecionada para todos os cursos que também formam profissionais da Educação na Instituição em análise, por meio do Projeto Institucional. No entanto, a forma como esse componente curricular foi configurado no curso de Pedagogia considerou, também, as experiências anteriores pelas quais o curso passou.

Além de procurar fazer um trabalho interdisciplinar entre disciplinas e professores, desenvolver o princípio da pesquisa, como mostraremos adiante, o Pipe, na perspectiva de buscar a unidade teórica e prática, procurou, também, oportunizar um contato do aluno com a prática desde o início do curso. A configuração dessa proposta caminha na direção de ter a própria prática como lugar da unidade entre teoria e prática.

\footnotetext{
a articulação das diferentes práticas, numa perspectiva interdisciplinar. $\S 1^{\circ} \mathrm{A}$ prática será desenvolvida com ênfase nos procedimentos de observação e reflexão, visando à atuação em situações contextualizadas, com o registro dessas observações realizadas e a resolução de situações-problema”. A Resolução CNE/ CP n 02/2002, na alínea I, do artigo 1, propôs “400 (quatrocentas) horas de prática como componente curricular, vivenciadas ao longo do curso". Para atender a essas exigências legais, um dos encaminhamentos foi instituir o Pipe como componente curricular.
} 
O referido componente curricular tem a intenção de trazer na sua dinâmica de funcionamento a perspectiva de inovação, pela possibilidade de desenvolver práticas interdisciplinares. Todavia, sua operacionalização tende a não ser tarefa simples, já que no cenário educacional a presença da cultura disciplinar e fragmentada do conhecimento está fortemente impregnada nos currículos.

Além dessa tradição disciplinar, outro aspecto que poderá dificultar o desenvolvimento do Pipe concerne ao entendimento que cada professor tem acerca desse componente curricular. Para muitos, ele é uma disciplina que se assemelha a de Metodologia e Técnicas de Pesquisa - MTP - e não um projeto numa perspectiva integradora. Ou seja, para alguns professores, o Pipe foi compreendido como uma disciplina e não como um projeto que busca, além da unidade teoria e prática, envolver o corpo docente para um trabalho coletivo e interdisciplinar, no ponto de vista da pesquisa como eixo norteador. Essa falta de compreensão acerca do Pipe é um fator que também tende a contribuir para dificultar sua operacionalização de forma articuladora.

O Pipe I e Pipe II, desenvolvidos na primeira e segunda série, respectivamente, têm seu ponto alto no Seminário de Prática Educativa e seu ponto contínuo nas atividades a serem realizadas por meio do Estágio Supervisionado. O Seminário de Prática Educativa possui carga horária de vinte horas e ao final dessa etapa cabe ao aluno apresentar um relatório síntese das atividades efetuadas durante o Pipe. Isso pode acarretar um enriquecimento na formação profissional, pois o Seminário se constitui em uma exposição permeada por debates promovidos por um grupo de alunos, onde, em geral, ocorrem trocas de ideais, de experiências, alargamento do conhecimento de outras culturas e realidades.
A configuração do Estágio no PPC de Pedagogia da Instituição pesquisada procurou colocar o aluno em contato com a realidade desde o início do curso, por meio do Pipe, no intuito de evitar que o referido componente curricular se caracterizasse simplesmente como atividade puramente burocrática de preencher fichas e relatórios para cumprir determinada carga horária preestabelecida.

Diante disso, o Estágio Supervisionado I privilegiará atividades de cunho teórico e prático, com o objetivo de possibilitar a construção de diagnóstico da instituição escolar e gradativa inserção e participação em projetos e ações desenvolvidas pela escola. Já o Estágio Supervisionado II, em continuidade ao I, privilegiará a prática profissional na docência e na gestão educacional no âmbito dos processos de ensino e nas dimensões relativas ao trabalho pedagógico.

No Estágio, a pesquisa se estabelece como espaço de aprofundamento de estudos sobre o trabalho do pedagogo. De tal forma, a configuração do Pipe, Seminário e Estágio tendem a possibilitar maior vinculação entre os sistemas de ensino e as instituições formadoras.

Convém lembrar que tanto o Pipe quanto o Estágio trazem elementos a serem objetos de reflexão. Para isso, não se pode apenas colocar pura e simplesmente o aluno em contato com a escola. É necessário que ele seja impulsionado a ir além do conhecer, é preciso que ele também reflita sobre o modo como tal realidade apresentada foi gestada.

Com relação à pesquisa como princípio formativo, meio de produção de conhecimento e intervenção na prática social, entendemos que ela deve ser o ponto de partida e de chegada do processo de formação docente. Articulada a uma sólida fundamentação teórica, foi compreendida no PPC como um eixo 
a ser trabalhado durante todo curso e na prática pedagógica de cada professor.

A proposta de partir da prática desde o início do curso converge para um ensino indissociável da pesquisa, pois conforme menciona Cunha (2000, p. 30): "Do ponto de vista de uma proposta pedagógica de ensino indissociável da pesquisa, a questão, então, é perguntar-se como nasce a dúvida intelectual, aquela que move o sujeito no sentido de debruçá-lo sobre o objeto do conhecimento”. A própria autora explicita que:

Parece ser na trajetória experencial que isso acontece, pode-se perceber que a dúvida nasce da observação e da leitura da prática do campo de conhecimento que a pessoa vive ou se propõe a estudar. Só a prática e a realidade são as fontes capazes de gerar a dúvida intelectual que, por sua vez, mobília a pesquisa. (CUNHA, 2000, p. 30).

Dessa forma, faz sentido configurar a organização curricular para superar a lógica tradicional dos currículos, em especial do curso de Pedagogia, em que a prática sempre fora colocada no final do curso, de tal forma que o aluno não fazia da leitura prática o ponto de partida para a construção da dúvida epistemológica. A prática, nesse contexto, não era a referência para a teoria. Ao contrário, a teoria era a referência para a prática (CUNHA, 2000).

A sugestão configurada no PPC de Pedagogia pesquisado converge para a direção que associa o ensino com a pesquisa desde o início do curso. Assim, o aluno observa e faz uma leitura da prática do campo de conhecimento expressado no PPC, ou seja, da escola, do trabalho pedagógico.

Tomando a perspectiva de se trabalhar na interdisciplinaridade e tendo a pesquisa e a prática pedagógica como atividades fundamentais basilares para o curso, “[...] buscou-se criar espaços para a abordagem do fenômeno educativo e da prática pedagógica, permitindo, ao futuro pedagogo, compreender, analisar e sistematizar experiências sobre a realidade educacional, objeto de sua atuação profissional” (PPC DE PEDAGOGIA, 2005/2006, p. 10).

Para uma das professoras entrevistadas, porém, não há como focar a escola como objeto se não houver um conhecimento prévio dos elementos de pesquisa. Essa professora advoga que é necessária uma disciplina a priori que discuta a pesquisa, seus princípios e métodos. Todavia, essa visão se distancia da pesquisa como eixo formativo e epistemológico da organização do currículo que deverá permear todo o curso, como é preconizado no PPC.

Pelos depoimentos e leitura do PPC, evidenciamos que a concepção fundante de desenvolver o Pipe fundamentado na pesquisa foi na expectativa de dar sentido à "ida" do aluno à escola para contextualizar, fundamentar, problematizar teoricamente o que ele tem visto e vivenciado no dia a dia das instituições por ele visitadas.

A interdisciplinaridade deveria partir da prática dos professores, no sentido de dialogarem entre si e proverem medidas, ações que aproveitassem ao máximo a experiência do aluno nesse contato com a escola, que é um espaço dinâmico, onde múltiplos conhecimentos do trabalho pedagógico estão borbulhando, tais como as práticas da avaliação, da gestão, do ensino, da pesquisa, da própria construção do conhecimento escolar e outras.

Com relação ao desenvolvimento da pesquisa construída no PPC, na perspectiva do Pipe, entre os professores entrevistados há aqueles que não comungam do estabelecido no Projeto. Uma das professoras é a favor da redistribuição direta da carga horária 
estabelecida pelas Resoluções CNE/CP $n^{\circ}$. 01/2001 e CNE/CP n ${ }^{\circ}$. 02/2002 a cada docente, ao invés de se utilizar o Pipe. Por um lado, acreditamos que se poderia abrir um tempo cronológico para o professor desenvolver a pesquisa conexa com sua disciplina, mas por outro lado o trabalho interdisciplinar - que é também uma proposta do Pipe - ficaria comprometido. Em sua ação docente, o professor precisa cogitar possibilidades integradoras de trabalho, e isso implica refletir, abordar um determinado elemento pedagógico no ponto de vista de várias disciplinas, não ficando restrito ao olhar unidisciplinar.

A interdisciplinaridade vai além das fronteiras. Nesse processo, tem-se a probabilidade de articular vários conhecimentos para estudar um evento pedagógico específico, o que poderá ocasionar uma abertura no campo de visão do aluno. E ao reforçar ainda mais a cultura disciplinar, oferecendo apenas horas para os professores trabalharem individualmente suas disciplinas específicas, além de colaborar para mantê-los em espaços de disciplinarização, inibiremos os diálogos, trocas de ideias e debates sobre variados temas, dificultando a discussão sobre o próprio objetivo do curso.

Ao promover os princípios supracitados, buscou-se, ainda, proporcionar ao alunado desse curso o desenvolvimento de outro princípio, o da sólida formação teórica e interdisciplinar, o qual implica o domínio dos conteúdos a serem ensinados pela escola e reflexões sobre a educação, seus campos e métodos de estudo, status epistemológico, com o auxílio de diversas áreas do conhecimento (ANFOPE, 2008). O curso de Pedagogia pesquisado desenvolveu esse princípio ao propor uma mudança no seu desenho curricular e levar em consideração as suas vivências anteriores.

A sólida formação teórica foi no sentido de fazer com que o aluno não se distan- ciasse do curso durante os quatros anos de formação, pois isso prejudicava o diálogo com o professor e as trocas de ideias e experiências entre seus pares.

O princípio da sólida formação teórica e interdisciplinar, desenvolvida no curso em análise, tende a proporcionar ao graduando a compreensão das bases de seu contexto e a apropriação do processo de trabalho pedagógico a partir da realidade, o que dependerá, em grande parte, da abordagem que o professor faz na disciplina que ficou sob sua responsabilidade para atender à proposta construída e configurada no PPC. Vale ressaltar que a disciplina isolada não contribui para uma formação global e sim para uma formação mais fragmentada. Assim, é necessário, conforme enfatiza Pinheiro (2006, p. 92), “[...] a superação do distanciamento entre projeto coletivo e propostas individuais [que] depende mais do exercício constante de discussão do que de decisões consensuais”.

Analisamos o princípio da flexibilidade curricular a partir da organização curricular presente no PPC de Pedagogia em foco. Ele é compreendido “[...] como a capacidade, a possibilidade do currículo dialogar com os limites e os novos campos de saberes" (PPC DE PEDAGOGIA, 2005/2006, p. 7). Essa questão, registrada no documento "Concepções e Implementação da Flexibilização Curricular"4, refere-se a algo imposto nas reformas curriculares dos cursos de graduação devido às exigências das transformações socioeconômicas, geopolíticas, culturais e tecnológicas que vêm ocorrendo na sociedade contemporânea, com seus desdobramentos

\footnotetext{
4 Documento este fruto das discussões realizadas nos Grupos de Trabalho - GTs constituídos durante a realização do XVI Encontro do Fórum Nacional de Pró-Reitores de Graduação das Universidades Brasileiras - Forgrad realizado na cidade de Campo Grande-MS, em 2003.
} 
gerais e particulares na educação, em específico, no ensino superior (FORGRAD, 2009), pois busca superar a lógica da racionalidade técnico-científico-instrumental presente nas práticas institucionais.

No referido documento, o Fórum Nacional de Pró-Reitores de Graduação das Universidades Brasileiras - Forgrad traçou alguns pontos na tentativa de contribuir para a elaboração de Projetos Pedagógicos, de modo a reafirmar o compromisso social e a responsabilidade ético-política das universidades com a sociedade brasileira. Esses pontos devem nortear toda e qualquer ação pedagógica de flexibilização curricular, respeitando, claro, as características das diferentes IES.

Como já afirmamos, o curso de Pedagogia pesquisado trabalhou, em partes, a questão da flexibilidade. As atividades complementares estão registradas no final do desenho curricular, não como apêndice, pois o aluno até o terceiro ano tem que ter realizado $75 \%$ da quantidade de horas, ou seja, as atividades complementares devem ser integralizadas ao longo do estudo.

No documento do Forgrad, a ideia que se propõe é de que o aluno desenvolva sua autonomia no sentido de buscar outros momentos que contribuam para a sua formação, tais como eventos científicos da área e participação em projetos de pesquisa. Assim, o curso de Pedagogia examinado, ao propor as Atividades Complementares, caminha também na direção defendida pelo Forgrad.

As disciplinas optativas, que também se constituem em meios para integralizar as Atividades Complementares, são obrigatórias no currículo. No entanto, o aluno tem a opção de fazer outra disciplina optativa, ou seja, poderá somar 120 horas de disciplinas optativas.

Partindo desses pontos traçados pelo Forgrad e pelas análises desenvolvidas acerca do PPC, é perceptível que a interface real entre ensino, pesquisa e extensão ainda não foi contemplada no PPC de Pedagogia em análise. Apesar de haver sugestões de articulação entre ensino e pesquisa ao longo do curso, a extensão se localiza nas Atividades Complementares.

Um outro ponto a considerar é que a comentada flexibilização curricular nos leva a idealizar currículos mais flexíveis, e o currículo do Curso de Pedagogia em análise é rígido, está estruturado ainda por disciplinas regulares. Operacionalizar o discurso da flexibilidade curricular ainda se constitui em uma tarefa difícil devido às lógicas curriculares presentes no interior dos cursos de graduação, em especial no de Pedagogia, que por muito tempo foi regido pelos currículos mínimos. E além dessa tradição curricular, cabe lembrar, conforme explicita Goodson (2000, p. 117) que:

A estruturação da educação em disciplinas
representa em primeiro lugar a fragmen-
tação e internalização das brigas sobre
educação no Estado: fragmentação, por-
que os conflitos acontecem em uma gama
de disciplinas compartimentalizadas; in-
ternalizadas, porque os conflitos agora
acontecem não apenas dentro da escola,
mas também com relação aos limites das
disciplinas.

Vale aqui enfatizar que a organização curricular sempre provoca discussões, porque o currículo se constitui como uma luta por território, que envolve relações de poder (FOUCAULT, 2000) e, conforme afirma Goodson (1997, p. 27), “[...] está longe de ser uma unidade construída desapaixonadamente e é, de facto, um terreno de grande contestação, fragmentação e mudança” [sic]. Portanto, a reestruturação no currículo não é apenas uma ação individual, mas uma reflexão e ação sobre práticas anteriores, no 
sentido de se construir novas práticas que poderiam visar a uma qualidade na formação que se deseja.

Uma disciplina escolar é construída social e politicamente, envolvendo em seu interior dimensão de cunho ideológico, epistemológico, social e político. Além dessa característica particular de ser da disciplina, a organização de um currículo em IES considera a disposição de seu corpo docente, pois ao construir um PPC carece também avaliar o grupo de profissionais efetivos, concursados, que já fazem parte do curso. Entretanto, isso não significa dizer que não há como buscar a flexibilidade; implica propiciar formas de criatividade, diálogo entre os envolvidos nesse processo, de modo a prover formas de atingir esse princípio.

Assim, seriam necessárias algumas reflexões, tais como: qual o objetivo maior que norteia o curso? Onde e como a disciplina que está sob a responsabilidade de determinado professor pode contribuir para alcançar o objetivo? Como a disciplina que ministra pode dialogar e concorrer para o andamento das demais disciplinas do curso? São reflexões que consideramos importantes pensar, no sentido de ter especificado flexibilidade curricular para que e para quem.

Quanto aos demais princípios, como a incorporação da concepção de formação continuada, esta vem, segundo a Anfope (2008), em contraposição à ideia de currículo e formação extensiva, sem comprometer a formação teórica qualitativa. Contudo, quando se tem a docência entendida na perspectiva para além da sala de aula, essa acepção demonstra a necessidade de se pensar na formação contínua, uma vez que os conhecimentos escolares não são neutros e acompanham o desenvolvimento tecnológico e científico da sociedade.

Nos depoimentos dos professores, ficou evidente que o curso de Pedagogia pesquisado proporcionará uma base, e por ser a educação um campo vasto, caberá ao aluno, por meio da atualização constante, focar e acompanhar a sua área de interesse. Dessa forma, afirmamos que não é o curso que vai dar conta de toda dimensão formativa, mas a formação do pedagogo também se fará no processo, na formação continuada.

Outro princípio, o do compromisso social, ético, político e técnico do profissional da educação se refere, conforme consta no PPC de Pedagogia examinado, a um profissional historicamente situado, apto a compreender e agir na sociedade em que vive; a fazer uma análise política da educação e das lutas históricas dos educadores, articulando-as com movimentos sociais mais amplos (PPC DO CURSO DE PEDAGOGIA, 2005/2006).

Com relação a esse princípio, uma das professoras explicou que sua efetivação será promovida pelos demais, principalmente, pela sólida formação teórica. O compromisso social, ético, político e técnico enfatiza um pacto do pedagogo com a sociedade da qual ele faz parte, envolvendo, ao mesmo tempo, uma concepção sócio-histórica do profissional da educação e a sua opção política, por meio da análise política da educação, das lutas históricas travadas nesse campo. Esse princípio ainda requer do profissional uma base técnica, ou seja, análise e encaminhamento de problemas e situações próprias de sua área de conhecimento, no sentido de prover técnicas e metodologias de ensino para auxiliar na apresentação e construção do conhecimento na perspectiva dialética. Todo esse processo exige desse profissional uma postura ética, uma ética universal, como preconiza Freire (2008, p. 18): “[...] ética enquanto marca da natureza humana, enquanto algo absolutamente indispensável à convivência humana”.

Outro princípio defendido pela Anfope é o trabalho coletivo e a gestão democrática, 
que são considerados a base para a construção e desenvolvimento de um Projeto Pedagógico no âmbito de um curso. Experienciar formas de gestão democrática significa superar o conhecimento de administração enquanto técnica, na direção de um sentido mais amplo do significado social das relações de poder que se reproduzem no cotidiano da escola, nas relações entre profissionais, entre estes e os alunos, assim como na concepção e elaboração dos conteúdos curriculares que contemplem a multiplicidade de dimensões da formação humana (ANFOPE, 2008).

Esse princípio se aplica não apenas à estruturação específica do curso em foco, mas, ainda,

[...] a qualquer organização curricular, em contextos escolares e não escolares, e aponta para uma nova maneira de compreender o currículo e sua operacionalização e nos remete ao campo das relações e práticas que se constroem e se desenvolvem no cotidiano dos processos formativos. (PPC DO CURSO DE PEDAGOGIA, 2005/2006, p. 10).

Considerando as análises anteriores, o princípio do trabalho coletivo e da gestão democrática está inserido dentro da perspectiva do currículo em seu todo, notadamente no desenvolvimento do Pipe, do Seminário e Estágio. Estes são componentes curriculares que para serem bem sucedidos requerem substituir a organização regida pelos princípios da divisão do trabalho, da fragmentação e do controle hierárquico, pelo trabalho coletivo e diálogo entre professores, coordenação e alunos.

A partir do desenvolvimento desses princípios assentados na ideia da docência como base, mesmo o PPC listando os mais diversos campos de atuação do pedagogo, tem-se “[...] a clareza de que a educação formal e escolar ainda é o lócus privilegiado de inserção desse profissional” (PPC DO CURSO DE PEDAGOGIA, 2005, p. 09).

Entre fios, entendidos como princípios norteadores: a relação teoria e prática e ênfase na pesquisa como produção de conhecimento; sólida formação teórica e interdisciplinar; gestão democrática; compromisso social, político e ético; trabalho coletivo e interdisciplinar; e incorporação da concepção de formação continuada, foi-se configurando uma teia compreendida como a base comum, a docência. Na perspectiva de se construir um curso assentado nessa base, ou melhor, para a edificação dessa teia, foi preciso tecer relações, entrelaçando os fios.

\section{Considerações finais}

A apreensão da docência a outras dimensões do trabalho pedagógico é reconhecida como um esforço das entidades da área educacional, em particular da Anfope, para incorporar suas reivindicações históricas no texto das DCNP. De tal forma, a docência, uma das reivindicações atendidas pelo CNE, acompanha o sentido concebido por essas entidades, ou seja, não é restrita às funções de ensino na sala de aula, mas compreende as funções tanto de professor quanto de gestor e pesquisador.

Nessa direção, as informações obtidas durante o desenvolvimento deste estudo permitiram evidenciar que a docência é um princípio base que orientou a construção do PPC de Pedagogia pesquisado. A concepção dessa base implicou assumir certos princípios, ou seja, foi necessário analisar a teia de inter-relações complexas constituídas a partir dos fios, princípios norteadores que procuram se articular formando um todo no curso e buscam dar sustentabilidade à ideia de docência como base que se integra à concepção de pesquisa e gestão. 
Esses princípios norteadores que dão forma à docência não se constituem em uniformidades agregadas meramente no sentido de apenas ocupar um espaço no projeto. Há no PPC uma complexidade de elementos que são intercomplementares e indispensáveis para a compreensão e operacionalização do todo.

Destacaram-se nesse processo de configuração: reestruturação da grade curricular e das atividades acadêmicas; redimensionamento dos conteúdos trabalhados; introdução de novas modalidades pedagógicas; inserção do estudante no campo de atuação desde os anos iniciais; ação interdisciplinar, unidade teoria e prática. Essa nova configuração estabelecida no PPC do curso de Pedagogia transcendeu a simples reestruturação do lugar e tempo de cada disciplina no currículo.

Claro está que o êxito do desenvolvimento da docência como base comum, articulada à pesquisa e à gestão, configurada no PPC de Pedagogia analisado, dependerá, em grande parte, do trabalho individual e coletivo do professor. Individual, devido ao currículo do curso permanecer estruturado disciplinarmente, ficando a cargo do professor, por meio do desenvolvimento da disciplina, a articulação da docência com a pesquisa e a gestão. Coletivo, porque a implementação de um projeto jamais se faz de maneira singular, ou seja, é necessário um movimento dialético uno e diverso simultaneamente.

Enfim, ressaltamos que um PPC com essa estrutura, com essas mudanças não se constitui em uma tarefa de simples implementação. A efetivação de um PPC não é isenta de dificuldades, até mesmo para discutir essa questão seriam necessários mais elementos. No entanto, como a finalidade particular deste estudo não foi essa, apenas indicamos que a implementação é um pro- cesso que merece investigação por ser algo novo, já que as DCNP foram aprovadas em 2006.

\section{Referências}

AGUIAR, M. Â. et al. Diretrizes curriculares do curso de pedagogia no Brasil: disputas de projetos no campo da formação do profissional da educação. Revista Educação e Sociedade, Campinas, v.27, n.96, p.819-842, out. 2006. Edição Especial.

\section{ANDRÉ, M. E. D. A. Estudo de caso em pesquisa e avaliação educacional. Brasília: Líber Livro, 2005.}

ANFOPE. Documento final/ano 1994. Disponível em: <http://www.lite.fae.uicamp.br/ anfope $>$. Acesso em: 10 set. 2008.

ANFOPE. Documento gerador. Goiânia, GO, 2008, 29 p.

BRASIL. Resolução CNE/CP n n 01/2002. Institui as Diretrizes Curriculares Nacionais para a formação de professores da educação básica, em nível superior, curso de licenciatura, de graduação plena. Diário Oficial da União, Brasília, DF, 09 abr. 2002, Seção 1, p. 31. (Republicada por ter saído com incorreção do original do D.O.U. de 04 de março de 2002. Seção 1, p. 8).

Resolução CNE/CP n n 02/2002. Institui a duração e a carga horária dos cursos de licenciatura, de graduação plena, de formação de professores da educação básica em nível superior. Diário Oficial da União, Brasília, DF, 04 ma. 2002, Seção 1, p. 9.

. Conselho Nacional de Educação. Resolução $n^{0}$ 1/2006. Institui Diretrizes Curriculares Nacionais para o Curso de Graduação em Pedagogia, licenciatura. 
Diário Oficial da União, Brasília, 16 mai. 2006c, Seção 1, p.11.

CATANI, A. M.; OLIVEIRA, J. F.; DOURADO, L. F. Política educacional, mudanças no mundo do trabalho e reforma curricular dos cursos de graduação no Brasil. Revista Educação e Sociedade, Campinas, ano 22, n. 75, p. 67-83, ago.2001.

CRUZ, G. B. O curso de pedagogia no Brasil na visão de pedagogos primordiais. 2008. 302 f. Tese (Doutorado em Educação) - Programa de Pós-Graduação em Educação, Pontifícia Universidade Católica do Rio de Janeiro, Rio de Janeiro, 2008.

CUNHA, M. I. Aportes teóricos e reflexões da prática: a emergente reconfiguração dos currículos universitários. In: MASETTO, M. T. Docência na universidade. 3. ed. Campinas, SP: Papirus, 2000. p. 27-38.

FORGRAD. Concepções e implementação da flexibilização curricular. Disponível em: $<$ http://www.forgrad.ufam.edu.br/arquivo/ documento_conc_e_impl_flex_curricular. doc>. Acesso em: set. 2009.

FOUCAULT, M. Ciência e saber: In:

A arqueologia do saber. 6.ed. Rio de Janeiro: Forense Universitária, 2000.

FREIRE, P. Pedagogia da autonomia: saberes necessários à prática educativa. 37. ed. São Paulo: Paz e Terra, 2008.

GOODSON, I. A construção social do currículo. Lisboa: Educa, 1997.

A crise na mudança curricular: algumas advertências sobre iniciativas de reestruturação. In: SILVA, Luiz Heron da. (Org.). Século XXI: qual conhecimento? Qual currículo? Petrópolis: Vozes, 2000.

HOUAISS, A. Minidicionário Houaiss da língua portuguesa. 2. ed. Rio de Janeiro: Objetiva, 2004. 976 p.
LIBÂNEO, J. C. Diretrizes Curriculares da Pedagogia: um adeus à Pedagogia e aos Pedagogos? Disponível em: <http:// www.ced.ufsc.br/pedagogia/Textos/ JoseCarlosLibaneo.htm>. Acesso em: 25 ago. 2009.

MALANCHEN, J.; VIEIRA, S. R. A política brasileira de formação de professores: repercussões sobre o trabalho docente. 2006. Disponível em: <http://www.fae.ufmg.br/ estrado/cd_viseminario/trabalhos/eixo_ tematico_1/a_politica_brasiliera_de_form. pdf $>$. Acesso em: 25 ago. 2009.

MARTINS, F. J. M. Pedagogia e docência no Brasil. In: Congresso Internacional do Centro de Investigação, Difusão e Intervenção Educacional - CIDInE, 2: Novos contextos de formação, pesquisa mediação, Vila Nova de Gaia - Portugal, 2009. Anais... p. 1-10.

PINHEIRO, M. E. A ação coletiva como referencial para a organização do trabalho pedagógico. In: VEIGA, I. P. A.; RESENDE, L. M. G. Escola: espaço do projeto político-pedagógico 10. ed. Campinas, SP: Papirus, 2006.

UFU/FACED. Projeto Pedagógico do curso de Pedagogia (2005/2006). Arquivo da secretaria do curso de Pedagogia. 2005/2006. Faculdade de Educação - FACED -. Universidade Federal de Uberlândia - UFU.

RODRIGUES, M. F.; KÜENZER, A. Z. As diretrizes curriculares para o curso de Pedagogia: uma expressão da epistemologia da prática. In: Novas subjetividades, currículos, docência e questões pedagógicas na perspectiva da inclusão social. Encontro Nacional de Didática e Prática de Ensino. Recife: ENDIPE, 2006, p. 185 - 212.

SAVIANI, D. A pedagogia no Brasil: história e teoria. Campinas, SP: Autores Associados, 2008. 
TRICHES J. Curso de pedagogia: a hegemonia da docência. Florianópolis, 2007. Relatório Final de Pesquisa

VÁZQUEZ. A. S. Unidade entre teoria e prática. In: Filosofia da práxis. 2.ed. Rio de Janeiro: Paz e Terra, 1977. p. 209-245.

Enviado em: 17/11/2009

Aceito em: 16/02/2011 